\title{
Implementation and evaluation of a team approach to managing diabetes mellitus and diabetic retinopathy in the South African district health system
}

\begin{tabular}{|c|c|}
\hline $\begin{array}{l}\text { Authors: } \\
\text { Zaheera Abdo } \\
\text { Kovin Naidoo } \\
\text { Linda Visser }\end{array}$ & ${ }^{1}$ \\
\hline $\begin{array}{l}\text { Affiliations: } \\
{ }^{1} \text { Department o } \\
\text { Allied Health S } \\
\text { Voortrekker Ho } \\
\text { Mokopane, So }\end{array}$ & $\begin{array}{l}\text { f Optometry, } \\
\text { upport Services, } \\
\text { spital, } \\
\text { th Africa }\end{array}$ \\
\hline $\begin{array}{l}{ }^{2} \text { African Vision } \\
\text { Institute, Univ } \\
\text { KwaZulu-Natal } \\
\text { South Africa }\end{array}$ & $\begin{array}{l}\text { Research } \\
\text { ersity of } \\
\text { Durban, }\end{array}$ \\
\hline $\begin{array}{l}{ }^{3} \text { Department } \\
\text { Ophthalmolog } \\
\text { Clinical Medici } \\
\text { Mandela Scho } \\
\text { Durban, South }\end{array}$ & $\begin{array}{l}\text { y, School of } \\
\text { ne, Nelson R } \\
\text { ol of Medicine, } \\
\text { Africa }\end{array}$ \\
\hline $\begin{array}{l}\text { Corresponding } \\
\text { Zaheera Abdo } \\
\text { zaheera.abdoc }\end{array}$ & $\begin{array}{l}\text { author: } \\
\text { ol, } \\
\text { l1@gmail.com }\end{array}$ \\
\hline $\begin{array}{l}\text { Dates: } \\
\text { Received: } 30 \mathrm{~N} \\
\text { Accepted: } 25 \mathrm{~S} \\
\text { Published: } 17\end{array}$ & $\begin{array}{l}\text { Mar. } 2020 \\
\text { ept. } 2020 \\
\text { May } 2021\end{array}$ \\
\hline $\begin{array}{l}\text { How to cite th } \\
\text { Abdool Z, Naid } \\
\text { Visser L. Impler } \\
\text { evaluation of a } \\
\text { to managing di } \\
\text { and diabetic re } \\
\text { the South Afric } \\
\text { health system. } \\
\text { Health. 2021;8 } \\
\text { https://doi.org } \\
\text { v80i1.570 }\end{array}$ & $\begin{array}{l}\text { is article: } \\
\text { oo K, } \\
\text { nentation and } \\
\text { team approach } \\
\text { abetes mellitus } \\
\text { tinopathy in } \\
\text { an district } \\
\text { Afr Vision Eye } \\
0(1) \text {, a570. } \\
/ 10.4102 / a v e h .\end{array}$ \\
\hline $\begin{array}{l}\text { Copyright: } \\
\text { C 2021. The A } \\
\text { Licensee: AOS } \\
\text { is licensed und } \\
\text { Creative Comn } \\
\text { Attribution Lic }\end{array}$ & $\begin{array}{l}\text { uthor(s). } \\
\text { S. This work } \\
\text { ler the } \\
\text { nons } \\
\text { ense. }\end{array}$ \\
\hline Read online: & \\
\hline 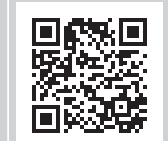 & $\begin{array}{l}\text { Scan this QR } \\
\text { code with your } \\
\text { smart phone or } \\
\text { mobile device } \\
\text { to read online. }\end{array}$ \\
\hline
\end{tabular}

Background: Diabetic retinopathy (DR) screening programmes have been developed and implemented in different countries based on availability of resources. Most protocols developed for DR have been solely dedicated to DR screening without involving systemic screening.

Aim: To implement and evaluate a DR screening model utilising a team of healthcare practitioners (HCPs) to manage diabetes mellitus (DM) to reduce DR progression.

Setting: Primary healthcare clinics and Voortrekker hospital in Waterberg district of Limpopo province.

Methods: A cross-sectional study was conducted, in which a total of 107 patients with DM from seven clinics consented to participation. A proposed DR screening model was implemented where patients with DM were screened for systemic complications at clinics and referred to Voortrekker district hospital for retinal photography. Questionnaire responses evaluated the success of the screening process and operational challenges.

Results: From the study population, 32 (29.1\%) were male and $75(70.1 \%)$ were female. The mean age of patients was 63.7 years with a mean weight of $80.69 \mathrm{~kg}$. The mean duration of DM was 9.26 years and the mean haemoglobin A1c (HbA1c) level was 9.7\%. From the 47 patients who had visual acuity less than 6/9, 74.5\% had refractive error. About 10\% (9.4\%) had DR or diabetic macular oedema (DME) and 38.3\% had other lesions. Referral to an ophthalmologist was necessary in $36.5 \%$ of cases.

Conclusion: The implementation of a team approach to co-manage DM and DR utilising the developed protocol improved the quality of care for patients with DM in the district health system.

Keywords: diabetes mellitus; diabetic retinopathy; screening programme; health care practitioners; district health system; primary health care.

\section{Introduction}

Diabetes mellitus (DM) is a global pandemic ${ }^{1}$ affecting patients in their most productive years. It is a lifestyle disease, unless genetically inherited, associated with modifiable risk factors such as hypertension and obesity, and non-modifiable risk factors such as ageing, ethnicity and family history. ${ }^{2}$ The microvascular and macrovascular complications of DM impact on patients' quality of life, contributing to high morbidity and mortality rates.

Microvascular and macrovascular complications in DM may develop simultaneously. ${ }^{3}$ Complications include cerebrovascular disease, cardiovascular disease (CVD), peripheral vascular disease, nephropathy, neuropathy and diabetic retinopathy (DR). The microvascular complications of DM are governed by the polyol pathway, which is activated by persistent hyperglycaemia. ${ }^{4}$ Hyperglycaemia is measured using an haemoglobin A1c (HbA1c) test, which assesses the average glucose level of the previous 2-3 month period. ${ }^{5}$ Poor HbA1c levels have been associated with the development and progression of DM complications. ${ }^{6}$ Macrovascular complications of DM have been found to be associated with insulin resistance more than hyperglycaemia. ${ }^{7}$ High insulin resistance has been found to increase CVD risk by 2.5 -fold. ${ }^{8}$

Insulin resistance and hyperglycaemia have also been driving factors in the development of nonalcoholic fatty liver disease (NAFLD). The spectrum of pathological conditions of NAFLD ranges 
from simple steatosis to non-alcoholic steatohepatitis to cirrhosis and hepatocellular carcinoma. ${ }^{9}$ Type 2 DM and obesity have been identified as risk factors for the development of NAFLD. ${ }^{10}$ It has been established that CVD risk increase by 1.87 -fold in patients with NAFLD in the presence of Type 2 DM. ${ }^{11}$ Non-alcoholic fatty liver disease also increases microvascular complications of DM such as chronic kidney disease and DR.12 The gold standard for diagnosing NAFLD is a liver biopsy to identify liver steatosis and carcinoma. However, in the absence of liver steatosis, the recommended treatment is a weight loss and exercise programme to enhance insulin sensitivity to promote the reduction of liver steatosis. ${ }^{13}$

Diabetic retinopathy, cataract and glaucoma are common ocular manifestations of DM. ${ }^{14}$ Uncorrected refractive errors (myopia, hyperopia and astigmatism) are generally a major cause of low vision and blindness. Low vision is defined by two categories, namely moderate visual impairment (VI), which is presented by visual acuity (VA) less than $6 / 18$ but equal to or better than $6 / 60$ and severe VI, which is presented by VA less than $6 / 60$ but equal to or better than $3 / 60 .{ }^{15}$ Factors responsible for uncorrected refractive errors include the lack of awareness and recognition of the problem, nonavailability of refractive services or inability to afford refractive services and cultural disincentives to compliance. ${ }^{15}$ Refractive changes in patients with DM can be acute or chronic or progressive as associated with an increase in myopia. ${ }^{16}$ An increase in crystalline lens thickness is known to increase the prevalence of late-onset myopia in patients with DM. ${ }^{17,18}$

Diabetic retinopathy has the potential to affect all patients with DM and severe DR has been associated with the presence of neuropathy and nephropathy. ${ }^{19}$ Patients with DR may not experience symptoms of vision loss until it becomes too late to treat, leading to irreversible blindness. Some patients with DR may only notice vision deterioration if they develop cataracts. Cataract is the most common ocular complication of DM and is considered a major cause of VI in patients with DM in developed and developing countries..$^{20}$ Patients with DM are $4-5$ times more likely to develop cataracts with an early onset. ${ }^{21}$ Despite advancement techniques for cataract surgery (phacoemulsification), poor VA following cataract surgery has been associated with posterior capsular opacification, post-operative cystoid macular oedema, diabetic macular oedema (DME) and worsening of DR in patients with DM. ${ }^{20}$

Patients with DM have an increased risk of developing primary open angle glaucoma (POAG). ${ }^{22}$ A glaucoma suspect is defined as an individual with clinical findings and/or a constellation of risk factors that indicate an increased likelihood of developing POAG. ${ }^{23}$ These clinical findings and risk factors range from having high intraocular pressure (IOP), optic nerve head or retinal nerve fibre layer (RNFL) appearances suggestive of glaucomatous damage, unexplained visual field defects and abnormal angles to a positive family history of glaucoma. ${ }^{24,25}$ An IOP greater than
$21 \mathrm{mmHg}$ was traditionally set as a criterion for the suspicion of glaucoma. ${ }^{26}$ Other studies have also used this criterion. ${ }^{14,25}$ It was observed from the study of Baisakhiya et al. ${ }^{27}$ that patients with poor glycaemic control had higher IOPs and Hymowitz et al. revealed that it was unlikely for patients with elevated $\mathrm{HbA1c}$ levels to have low IOPs. ${ }^{28}$

Ideally, in the holistic co-management of patients with DM, HCPs should be educating patients on systemic and ocular complications, which may arise when the DM is not adequately controlled. With the rising incidence of DM, there is a growing focus by HCPs towards assisting patients with DM management because self-management poses a challenge. ${ }^{29}$ Values for DM detection have been documented, yet these values may appear meaningless to the illiterate or uneducated and may be underestimated by them.

As a result of the asymptomatic nature of DR, early detection of DR is essential to prevent further progression and potential vision loss. Health education is meant to be promoted at each level of care in the district health systems (DHS) involving primary healthcare (PHC) nurses, medical officers (MOs), ophthalmic nurses and optometrists. However, concerns have been expressed regarding the lack of policies dedicated solely to eye health promotion in South Africa (SA) where policies have been dedicated to curative rather than preventative measures. ${ }^{30}$ Patients with DM require comprehensive management by a team of HCPs to manage both systemic and ocular complications to prevent and reduce the progression of blindness because of diabetic eye disease. This highlights the need for a DR screening model in the DHS to co-manage patients with DM and DR.

\section{Methodology}

An observational study using convenience sampling was employed whereby 201 patients with DM from the seven catchment area clinics for Voortrekker district hospital were recruited for participation from 01 October 2018 to 31 March 2019. From 201 recruited patients, 107 consented to participation (Table 1). The study made use of the input, processes and output approach (Appendix 1). The duration of the retinal screening process was from 08 April 2019 to 30 May 2019.

Visual acuity was assessed using a Snellen VA chart. A Tumbling E chart was used to assess VA of illiterate patients. A handheld autorefractor (measuring distance of $1 \mathrm{~m} \pm 5 \mathrm{~cm}$ ), known as the Eurofractor, was used to determine refractive error of patients with VA less than 6/9. The refractive error was subjectively refined using trial frame refraction. The i-Care tonometer was used to assess IOP and the Tomey nonmydriatic fundus camera (model TFC-1000 with resolution of $4096 \times 3072$ mega pixels and a field of view of 45 up to $80^{\circ}$ ) was used to capture retinal images.

After consenting to participation, patients were given appointment cards for their retinal screening dates by the 
PHC nurses and referred to the MO for blood testing and medical assessment. Transport arrangements were made for patients to be transported from the clinics to Voortrekker district hospital for the ocular screening assessment. Patients profile details (gender and age), case history (duration of DM, presence of hypertension, medication compliancy, presence of a meal plan, presence of neuropathy and family history of DM) and vital signs (weight, glycaemia, blood pressure and $\mathrm{HbA1c}$ levels) were documented on the record card by the PHC nurses prior to patients' arrival for retinal screening. Blood tests were also performed and results were analysed by the $\mathrm{MO}$ who recorded findings of cardiovascular, kidney and liver dysfunction on the record card prior to the retinal screening process. On patients' arrival, the optometrist (principal investigator) conducted the ocular screening tests as per protocol (VA assessment, pinhole test, refractive error, IOP assessment, retinal photography, DR screening and grading). Retinal photography images were graded using a combination of the Scottish Grading Classification System and United Kingdom National Grading Classification, whereas other ocular lesions were documented on the record card under other lesions (OL). Photographic images of both eyes of each patient were saved to a flash drive which was hand-delivered to the ophthalmologist at Mankweng hospital for DR grade verification and the verification of OL (such as cataract and glaucoma suspects). All retinal photographs were assessed and patients requiring referrals to the ophthalmologists were given appointment dates for referral to either Mankweng or FH Odendaal hospitals based on the equipment and treatment available at those institutions.

On completion of the screening process, satisfaction survey forms were distributed to all the HCPs involved in the screening programme to evaluate the screening process. These included 107 patients, 14 PHC nurses, one MO and one ophthalmologist. A modification of the approach was performed after conducting a strength, weakness, opportunity and threat (SWOT) analysis of the screening process. Based on the responses, recommendations were made to support the DR screening model.

Data were analysed using standard descriptive statistics (proportions and frequencies) to describe all categorical variables and mean with standard deviations for continuous variables. The Fisher's test was used to test for associations between categorical variables. Spearman's rank correlation coefficient tests were used to measure correlations between continuous variables and the Mann-Whitney $U$ tests were used to compare continuous variables between two groups because of non-normality and small samples.

\section{Ethical consideration}

Approval to conduct the study was received from the Biomedical Research Ethics Committee, University of KwaZulu-Natal (BREC reference no. 272/18). Ethical clearance was granted before commencement of the study.
Permission to conduct the research study was obtained from the Department of Health Limpopo Province and the respective Heads of Institutions at clinics and hospitals. Information relating to the study was provided and informed consent was obtained from all participants.

\section{Results \\ Results of implementation phase}

\section{Discussion}

Poor glycaemic control has been identified as an important predictor to the development and progression of DR. ${ }^{31}$ In this study, a correlation between the hyperglycaemic level and $\mathrm{HbA1c}$ level was found (Spearman's rho $=0.58$ ). Although $98.1 \%$ of patients were supposedly compliant with treatment for DM as seen in Figure 1, 77.3\% reflected HbA1c levels of $>$ $7 \%$ showing poor control of DM. Only $8.4 \%$ patients complied with proper meal planning. There was an association found between $\mathrm{HbA} 1 \mathrm{c}$ levels greater than $7 \%$ and hyperglycaemia levels greater than $10 \mathrm{mmol} / \mathrm{L}$ (Fisher's exact $=0.001$; Table 2). Cardiac markers to detect cardiovascular disorders and liver function test assessments were done on 64 out of 107 (59.8\%) patients. Of the 64 patients, 57 (89.1\%) suffered liver disorders, and this was unlikely due to NAFLD because of the low prevalence of obesity $(5.6 \%)$. It was, however, not established whether the high prevalence of liver disorders was because of alcohol abuse and/or nutritional deficiencies. Creatinine levels to assess kidney dysfunction were done on 55 out of 107 (51.4\%) patients.

Refraction was conducted in patients with VAs less than $6 / 9(32.7 \%)$ and myopia was the most common refractive error found. The study conducted by Gwinup and Villarreal ${ }^{18}$ established that patients with DM developed more myopia after the injection of glucose, which was because of the accumulation of by-products of glucose metabolism within the crystalline lens causing lens swelling and inducing myopia. An acute decrease in plasma glucose concentration has, therefore, been associated with hyperopia. ${ }^{18}$ In this study, of the 14 patients who had severe

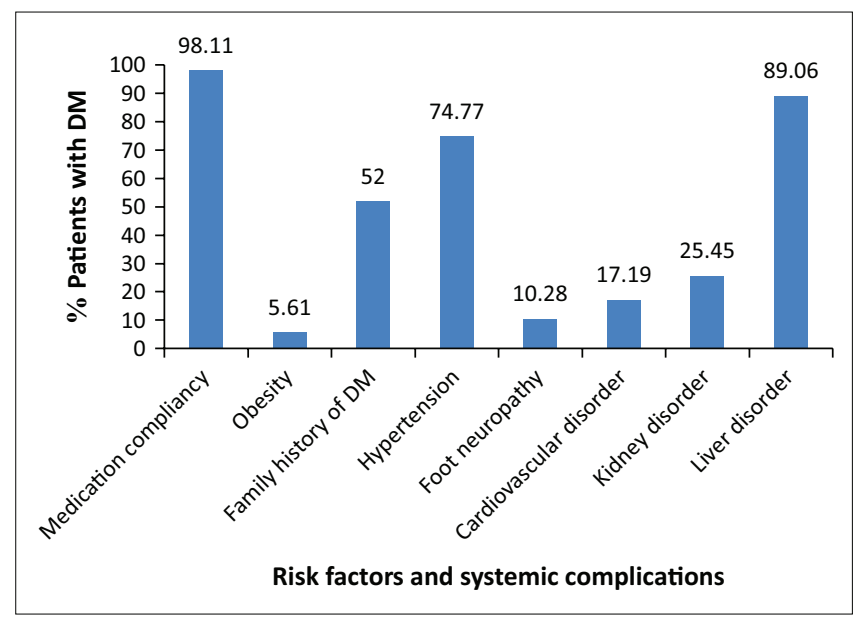

DM, diabetes mellitus.

FIGURE 1: Risk factors and complications associated with diabetes mellitus. 
TABLE 1: Database of 201 patients with diabetes mellitus and number of participants (107) who consented to participate in the screening programme.

\begin{tabular}{|c|c|c|c|c|}
\hline \multirow[t]{2}{*}{ Name of clinic } & \multicolumn{2}{|c|}{ Total number of patients with DM } & \multicolumn{2}{|c|}{ Total number of participants } \\
\hline & $n$ & $\%$ & $n$ & $\%$ \\
\hline Bokwalakwala clinic & 44 & 21.89 & 22 & 20.56 \\
\hline Ga-Madiba & 26 & 12.94 & 26 & 24.30 \\
\hline Gateway & 35 & 17.41 & 21 & 19.63 \\
\hline Mahwelereng 1 & 10 & 4.98 & 10 & 9.35 \\
\hline Mahwelereng 2 & 36 & 17.91 & 11 & 10.28 \\
\hline $\begin{array}{l}\text { Manyoga (new clinic; opened March } \\
\text { 2019) }\end{array}$ & 13 & 6.47 & 8 & 7.48 \\
\hline Sekgakgapeng & 37 & 18.41 & 9 & 8.41 \\
\hline Total & 201 & 100.00 & 107 & 53.23 \\
\hline
\end{tabular}

DM, diabetes mellitus.

TABLE 2: HbA1c levels greater than 7\% and hemo-glucose test levels greater than $10 \mathrm{mmol} / \mathrm{L}$

\begin{tabular}{|c|c|c|c|c|c|c|}
\hline \multirow[t]{3}{*}{ HbA1c } & \multicolumn{4}{|c|}{ HGT } & \multicolumn{2}{|c|}{ Total } \\
\hline & \multicolumn{2}{|c|}{$>10$} & \multicolumn{2}{|c|}{$\leq 10$} & & \\
\hline & $n$ & $\%$ & $n$ & $\%$ & $n$ & $\%$ \\
\hline$>7$ & 31 & 54.39 & 26 & 45.61 & 57 & 100.00 \\
\hline$\leq 7$ & 2 & 11.11 & 16 & 88.89 & 18 & 100.00 \\
\hline Total & 33 & 44.00 & 42 & 56.00 & 75 & 100.00 \\
\hline
\end{tabular}

Fischer's exact test: $p=0.001$

HGT, hemo-glucose test.

TABLE 3: Visual acuity, intraocular pressure, refractive error of patients with diabetes mellitus.

\begin{tabular}{lccccc}
\hline Categories & \multicolumn{2}{c}{ Right eyes } & & \multicolumn{2}{c}{ Left eyes } \\
\cline { 2 - 3 } \cline { 5 - 6 } & $n$ & $\%$ & & $n$ & $\%$ \\
\hline Visual acuity & 62 & 57.94 & & 60 & 56.07 \\
$\geq 6 / 9$ & 17 & 15.89 & & 20 & 18.69 \\
$6 / 12-6 / 18$ & 14 & 13.08 & & 16 & 14.95 \\
$6 / 18-6 / 60$ & 14 & 13.08 & & 11 & 10.28 \\
$\leq 6 / 60$ & 107 & 100.00 & & 107 & 100.00 \\
Total & & & & \\
Intraocular pressure & 105 & 98.13 & & \\
$<21$ & 2 & 1.87 & & 6 & 5.39 \\
$>21$ & 107 & 100.00 & & 107 & 100.00 \\
Total & & & & \\
Refractive error & 22 & 62.86 & & 22 & 62.86 \\
Myopia & 9 & 25.71 & & 9 & 25.71 \\
Hyperopia & 13 & 37.14 & & 12 & 34.29 \\
Astigmatism & 35 & 100.00 & & 35 & 100.00 \\
Total & 10 & 9.35 & & 7 & 6.54 \\
No pinhole improvement & & & & &
\end{tabular}

visual impairment (SVI), 71.4\% had myopia in the right eye and $75 \%$ in the left eye.

A total of $16(14.9 \%)$ patients were identified as glaucoma suspects. Of the 16 patients, eight $(50 \%)$ had IOP $>21 \mathrm{mmHg}$ (Table 3), whereas the other eight displayed optic discs or RNFL appearances suspicious of glaucomatous damage. In these patients, the ISNT rule (measurements of disc rim thickness of inferior $\geq$ superior $\geq$ nasal $\geq$ temporal $)^{32}$ was not obeyed. No correlation between IOP and $\mathrm{HbA1C}$ was found (Spearman's rho $=0.27$ for right eye and 0.18 for left eye). However, of the eight patients who had IOPs greater than 21 $\mathrm{mmHg}$, six (75\%) had $\mathrm{HbA1c}$ levels of more than $7 \%$ and this finding concurred with the studies of Baisakhiya et al. ${ }^{27}$ and Hymowitz et al. ${ }^{28}$ showing that patients with poor glycaemic control have higher IOPs. The HbA1c level in the other two patients was not assessed.
TABLE 4: Hypertension and glaucoma suspect per eye.

\begin{tabular}{|c|c|c|c|c|c|c|}
\hline \multirow[t]{3}{*}{ Presence of HPT } & \multicolumn{4}{|c|}{ Glaucoma suspect $(E Y E=O D)$} & \multirow{2}{*}{\multicolumn{2}{|c|}{ Total }} \\
\hline & \multicolumn{2}{|c|}{ No } & \multicolumn{2}{|c|}{ Yes } & & \\
\hline & $n$ & $\%$ & $n$ & $\%$ & $n$ & $\%$ \\
\hline \multicolumn{7}{|c|}{ Right eyes (EYE = OD) } \\
\hline No & 23 & 85.19 & 4 & 14.81 & 27 & 100.00 \\
\hline Yes & 68 & 85.00 & 12 & 15.00 & 80 & 100.00 \\
\hline Total & 91 & 85.05 & 16 & 14.95 & 107 & 100.00 \\
\hline \multicolumn{7}{|c|}{ Left eyes (EYE = OS) } \\
\hline No & 24 & 88.89 & 3 & 11.11 & 27 & 100.00 \\
\hline Yes & 68 & 85.00 & 12 & 15.00 & 80 & 100.00 \\
\hline Total & 92 & 85.98 & 15 & 14.02 & 107 & 100.00 \\
\hline
\end{tabular}

Fischer's exact test: $p=1.000$ for right eye and $p=0.756$ for left eye.

HPT, hypertension; $\mathrm{EYE}=\mathrm{OD}$, oculus dexter (right eye); $\mathrm{EYE}=\mathrm{OS}$, oculus sinister (left eye).

There was no association found between hypertension and glaucoma suspects (Fishers exact test; $p=1.000$ for right eye and $p=0.756$ for the left eye) as seen in Table 4 . The ocular complications co-existing with the glaucoma suspects included cataracts in three $(18.8 \%)$ patients, DR in two $(12.5 \%)$ patients and hypertensive retinopathy in one $(6.2 \%)$ patient.

Cataract was the most common ocular complication found (Table 5) causing blindness in six out of $11(54.6 \%)$ patients in the right eye and five out of 14 (35.7\%) in the left eye. Longer duration of DM has been associated with an increased frequency of cortical cataract and increased frequency of cataract surgery. ${ }^{33}$ In this study, there was no association found between the duration of DM and presence of cataract (Mann-Whitney U test; $p=0.65$ in the right eye and $p=0.32$ in the left eye). The median (IQR) duration of DM in the group with cataracts was $10(7-12)$ and $10(6-10)$ in the group without cataracts for the right eyes. For the left eyes, the medians (IQR) of $10(6-10)$ and 8 (5-10) were found in the groups with and without cataracts, respectively.

Two of the five patients with DR (40\%) and three of the four (75\%) with DME in the right eye showed poor control of their glycaemic level (HbA1c > 7\%). The HbA1c level of the other three patients with DR and one with DME was not tested. In the left eye, three of the five patients with DR $(60 \%)$ and two of the five with DME (40\%) showed poor glycaemic control. The HbA1c level of the two patients with DR and two with DME was not tested and only one patient with DME had an $\mathrm{HbA1c}$ level less than 7\%. 
TABLE 5: Diabetic retinopathy and other ocular lesions in 107 patients with diabetes mellitus.

\begin{tabular}{|c|c|c|c|c|}
\hline \multirow[t]{2}{*}{ Categories } & \multicolumn{2}{|c|}{ Right eyes } & \multicolumn{2}{|c|}{ Left eyes } \\
\hline & $n$ & $\%$ & $n$ & $\%$ \\
\hline \multicolumn{5}{|l|}{ DR and DME } \\
\hline Preproliferative DR & 5 & 4.67 & 5 & 4.67 \\
\hline Proliferative DR & 0 & - & 0 & - \\
\hline DME: & - & - & - & - \\
\hline Non-clinical significant DME & 3 & 2.80 & 4 & 3.74 \\
\hline Clinically significant DME & 1 & 0.93 & 1 & 0.93 \\
\hline Total & 9 & 8.41 & 10 & 9.35 \\
\hline \multicolumn{5}{|l|}{ Other ocular conditions } \\
\hline Cataract & 16 & 14.95 & 17 & 15.89 \\
\hline Glaucoma suspect & 16 & 14.95 & 15 & 14.02 \\
\hline Hypertensive retinopathy & 4 & 3.74 & 5 & 4.67 \\
\hline Myopic retinopathy & 1 & 0.93 & 1 & 0.93 \\
\hline $\begin{array}{l}\text { Peripapillary atrophy and } \\
\text { macular star }\end{array}$ & 1 & 0.93 & - & - \\
\hline Pterygium & 1 & 0.93 & 1 & 0.93 \\
\hline Retinal scar & 1 & 0.93 & - & - \\
\hline $\begin{array}{l}\text { Choroidal atrophy with myopic } \\
\text { crescent }\end{array}$ & - & - & 1 & 0.93 \\
\hline Previous retinitis & - & - & 1 & 0.93 \\
\hline Traumatic cataract & - & - & 1 & 0.93 \\
\hline Retinal detachment & - & - & 1 & 0.93 \\
\hline Total & 40 & 37.38 & 43 & 40.17 \\
\hline
\end{tabular}

$\mathrm{DR}$, diabetic retinopathy; DME, diabetic macular oedema.

Patients with pre-existing DME were found to have the worst prognosis for visual rehabilitation after cataract surgery. ${ }^{34,35}$ Treatment guidelines have been recommended for pre-existing DR and DME, which indicate annual screening for no DR and for mild non-proliferative DR (NPDR). ${ }^{36}$ A study conducted at a district hospital in SA revealed that $42.9 \%$ of patients with DM had refractive disorders and also confirmed that suspected glaucoma, cataracts and DR were prevalent eye conditions amongst patients with DM. ${ }^{37}$

From the patients' satisfaction survey in Table 6, the two patients who experienced transport problems utilised their own transport to the hospital for retinal screening. For one patient, this was by choice but the other missed the transport from the clinic because of late arrival and incurred a R50.00 travel cost. One patient waited for a long time at the clinic to be transported to the hospital for eye screening as she presented before 06:00 at the clinic and transport was scheduled for 09:00. More patients requested additional education on wound healing, foot care, dental care and blood pressure control than on diet and hyperglycaemia control. Some patients reported removing their own teeth and assumed that the use of false teeth does not require dental care. Additional information requested was on weight loss, urinary incontinence, body rash, management of headaches, hearing loss and advice on social grants because of unemployment. They also complained about suffering from other ailments such as cough, shortness of breath, swollen legs and getting chest irritation after taking ibuprofen. Other concerns raised were the unavailability of insulin injections, hypertension and DM treatment on certain days at clinics. In addition, they complained that on some days, blood pressure machines and glucometers were not working and occasionally
TABLE 6: Results of patients' satisfaction survey completed by 107 participants.

\begin{tabular}{|c|c|c|c|c|}
\hline \multirow[t]{2}{*}{$\overline{\text { Categories }}$} & \multicolumn{2}{|c|}{ Yes } & \multicolumn{2}{|c|}{ No } \\
\hline & $n$ & $\%$ & $n$ & $\%$ \\
\hline \multicolumn{5}{|l|}{ Screening process } \\
\hline Satisfied with screening process & 107 & 100.00 & & \\
\hline Transport challenges & 2 & 1.87 & 105 & 98.13 \\
\hline $\begin{array}{l}\text { Long duration of screening } \\
\text { process }\end{array}$ & & & 107 & 100.00 \\
\hline Long waiting period at clinic & 1 & 0.93 & 106 & 99.07 \\
\hline Incurred travel cost to clinic & 1 & 0.93 & 106 & 99.07 \\
\hline Experienced poor staff attitudes & & & 107 & 100.00 \\
\hline Poor communication by staff & & & 107 & 100.00 \\
\hline $\begin{array}{l}\text { Education given by staff at the } \\
\text { clinic helpful in controlling DM }\end{array}$ & 83 & 77.57 & 24 & 22.43 \\
\hline \multicolumn{5}{|l|}{ Additional education required for } \\
\hline Diet & 56 & 53.33 & 49 & 46.67 \\
\hline Foot care & 74 & 69.16 & 33 & 30.84 \\
\hline Blood pressure control & 61 & 57.01 & 46 & 42.99 \\
\hline Hyperglycaemia control & 49 & 45.79 & 58 & 54.21 \\
\hline Wound healing & 79 & 73.83 & 28 & 26.17 \\
\hline Dental care & 67 & 63.21 & 39 & 36.79 \\
\hline
\end{tabular}

DM, diabetes mellitus.

there were no glucose test strips. Another challenge was to get pills on time because of stock unavailability and misunderstanding of the dosages of alternative treatments prescribed when regular prescribed treatment was out of stock. At times no eye treatment was available at the clinics and hospital. There was not enough seating place at the clinics. A few reported that it was a challenge when it rained as they sit outside and when there is no shade this brings on headaches.

From the HCPs satisfaction survey in Table 7, the PHC nurses reported that the screening programme enhanced their knowledge and the knowledge of patients with DM. It was, however, a challenge to recall patients as their cell numbers were either on voicemail or no longer operational. At times, different test tubes were not available to collect blood samples. Patients were also not always compliant with treatment because of the unavailability of insulin injections at times. Occasionally, pills for high blood and DM were also not available. They suggested that the DR screening protocol be implemented for better service delivery as patients appreciated the opportunity of seeing the 'pictures of their eyes' for the first time. A staff member who was also a participant reported that the research was very helpful because of her own diabetic history. It was the first time that her blood was taken and tested. She was always worried about other undiagnosed conditions and never knew what her creatinine level was but now through this research, she had this opportunity to find out. Her sister passed on because of late diagnosis of liver disease; she was on dialysis after suffering from kidney failure. Another PHC nurse also reported that relatives of a patient were very pleased about the DR screening protocol as the patients' eye was operated within 2 months after being screened. The patient could now see better and manage to do things independently. The MO appreciated the effort demonstrated by the principal investigator to implement a team approach for early detection of DR. 
TABLE 7: Results of primary healthcare nurse and medical officers satisfaction survey completed by 15 primary healthcare nurses and one medical officers.

\begin{tabular}{|c|c|c|c|c|}
\hline \multirow[t]{2}{*}{ Screening process } & \multicolumn{2}{|c|}{ Yes } & \multicolumn{2}{|c|}{ No } \\
\hline & $n$ & $\%$ & $n$ & $\%$ \\
\hline Satisfied with protocol & 15 & 100.00 & 0 & - \\
\hline Sufficient space to screen patients & 14 & 93.33 & 1 & 6.66 \\
\hline Involvement in other screening programmes & 0 & - & 15 & 100.00 \\
\hline $\begin{array}{l}\text { Necessary equipment available to screen } \\
\text { patients with DM }\end{array}$ & 12 & 80.00 & 3 & 20.00 \\
\hline $\begin{array}{l}\text { Able to cascade information and knowledge of } \\
\text { the screening programme to colleagues }\end{array}$ & 15 & 100.00 & 0 & - \\
\hline
\end{tabular}

DM, diabetes mellitus.

The ophthalmologist reported seeing more than 100 DR cases per month and doing 60-70 laser photocoagulation treatments per month. The ophthalmologist was satisfied with the photographic images of the fundi and revealed that $80 \%$ of images were appropriately graded by the optometrist. She reported having sufficient space to examine and manage DR cases and also having treatment available for DR and DME. However, she reported not having sufficient staff to assist with DR cases and her request was for more ophthalmologists to be appointed to assist with DR case management.

\section{Strength, weakness, opportunity and threat analysis}

Strength: Staff revealed that patients were satisfied with the screening programme and wanted this programme to continue. There was an influx of patients making enquiries at the clinic about the booking system for retinal photography after the screening programme was completed. Patients reported never having been screened with a camera and appreciated the time taken on the additional education given on diet, foot care and dental care. The project's success was supported by the PHC nurses, MO on outreach, ophthalmologist and laboratory assistants. The PHC nurses saw the relevance of having a formal database for patients with DM. The MO in collaboration with the PHC nurses conducted the blood testing, which was sent to the laboratory at Voortrekker hospital for analysis and the progress could be easily tracked as the laboratory was on the premises of Voortrekker hospital.

Weakness: The commitment to provide a diabetic patient database from the data capturers working at the clinics was poor. In the absence of a diabetic patient database, the PHC nurses only recruited patients presenting at the clinic over a period of 6 months (October 2018 to Mach 2019). Patients' contact numbers on their files were non-existent and unreliable making it difficult to recruit more patients. A few blood pressure readings were not taken at the clinics because of nonoperational batteries. Blood samples were not taken of every patient because of the unavailability of test tubes on some screening dates. Some patients did not comply with going back to the clinics for retesting of blood. Certain markers that could not be analysed because of the restrictions in the laboratory facility had to be sent to the laboratory in Polokwane for analysis and a few blood samples were misplaced. Body mass index (BMI) could not be calculated by the PHC nurses because only weight was measured and not height.
Opportunity: Retinal photography created an opportunity to motivate patients for better glycaemic control. The goals of the screening programme are in line with those of the World Health Organisation (WHO), International Diabetes Federation (IDF) and National and Provincial Departments of Health. The programmes innovation could be replicated in other provinces and other parts of Africa. The programme offers an opportunity for training and employment for optometrists and ophthalmic nurses.

Threat: As a result of the lack of staff in the department, the screening programme was conducted by one optometrist who was the principal investigator.

\section{Conclusion}

The project showed feasibility to screen for DM and DR in a district health setting of SA. The screening model demonstrated improvement in quality of care of patients with DM and confirmed the importance and relevance of screening patients with DM to prevent development and progression of DR.

\section{Recommendations}

There should be more commitment from data capturers to organise databases for all patients with chronic illnesses. They should also capture more than one contact number of patients so that family members can be contacted if patients do not follow their review appointments. This will ensure better control and efficiency in follow-up to manage patients with DM. The involvement of community health workers will be beneficial to assist with patient recruitment and education on the importance of being tested for DM. This can be done by arranging campaigns highlighting symptoms and the associated complications of DM. The involvement of dieticians to assist and train PHC nurses to calculate BMI and educate patients on the importance of following proper meal plans will also be beneficial. Measuring scales and meter rulers for height assessment must be available at the clinics to determine BMI for obesity detection. The importance of blood testing should be emphasised to patients so that they see the need to be assessed for complications associated with DM. Furthermore, PHC nurses are to ensure that testing supplies are available and in good working condition for patient care at clinics, that is, blood pressure machines, glucometers, spare batteries and various blood testing tubes. Remodelling of clinics to create more working space and larger patient waiting areas will ensure more efficiency in the workplace. Staff recruitment needs to happen so that the DR screening model can be implemented by a team of HCPs dedicated to the programme.

The main aim in primary care is not to reach a specific diagnosis but to detect patients who are eligible for referral to be further managed. Healthcare practitioners (HCP) have to develop confidence in managing patients with DM and this can be achieved by engaging in group discussions with other HCPs, and by attending training courses for updates in management strategies and cascading information to other 
team members. Training programmes in retinal photography need to be introduced for optometrists and ophthalmic nurses working in the public sector especially because the use of nonmydriatic retinal photography has proven to be cost-effective in the DHS of SA..$^{38}$ Automated computer analysis of digital fundus images using smartphone would be a useful tool to enhance manual analysis by various HCPs. ${ }^{39}$ If the screening protocol is to be effectively implemented then all posts for optometrists and ophthalmologists need to be filled and posts for ophthalmic nurses in each district hospital need to be created. The continuation of the screening programme is dependent on various stakeholders at provincial and national level to incorporate this programme officially under the chronic management disease programme. This will, however, require essential resources to support the screening model.

\section{Acknowledgements}

The authors would like to thank Dr K. Seboghodi, Dr F. Stegmann, Dr L. van de Merwe, Dr M.P. Sesani and Dr A.K. Ismail for their inputs in developing the DR screening model; Dr T.M. Moabelo for photographic analysis of DR images; Eurotech Optical for equipment on loan and C.J. van Rensburg from the Medical Research Council for statistical analysis.

\section{Competing interests}

The authors declare that they have no financial or personal relationships that may have inappropriately influenced them in writing this article.

\section{Authors' contributions}

Z.A. was project leader, developed the protocol, collected and captured data, wrote up the research and prepared the draft for publication. K.N. and L.V. reviewed content of questionnaires for applicability, construct validity and reliability and provided guidance as supervisors to the writeup of the research thesis.

\section{Funding information}

This research received no specific grant from any funding agencies in the public, commercial or not-for-profit sectors.

\section{Data availability statement}

The data collected will be used solely for the purposes of completing my (Z.A.) research thesis and in future articles, journal articles and books that will be written by the author (Z.A.).

Additional information is available upon reasonable request from the corresponding author.

\section{Disclaimer}

The views and opinions expressed in this article are those of the authors and do not necessarily reflect official policy or position of any affiliated agency of the authors.

\section{References}

1. World Health Organisation. Global report on diabetes [homepage on the Internet]. Geneva: World Health Organisation, 2016; p. 6. Available from: https:// apps.who.int/iris/bitstream/10665/204871/1/1/9789241565257_eng.pdf

2. Harris $M$. Challenges in diabetes management. Aust Fam Physician. 2008;37(9):716-720.

3. Krentz AJ, Clough G, Byrne CD. Interactions between microvascular and macrovascular disease in diabetes: Pathophysiology and therapeutic implications. Diabetes Obes Metab. 2007;9(6):781-791. https://doi.org/10.1111/j.14631326.2007.00670.x

4. Mathebula D. Polyol pathway: A possible mechanism of diabetes complications in the eye. Afr Vis Eye Health. 2015;74(1):a13. https://doi.org/10.4102/aveh. v74i1.13

5. Kharoubi AT, Darwish HM. Diabetes mellitus: The epidemic of the century. World J Diabetes. 2015;6(6):850-867. https://doi.org/10.4239/wjd.v6.i6.850

6. Nicholas J, Charlton J, Dregan A, et al. Recent $\mathrm{HbA1}$ c values and mortality risk in type 2 diabetes: Population based case-control study. PLoS One. 2013;8(7):e68008. https://doi.org/10.1371/journal.pone.0068008

7. Fowler MJ. Microvascular and macrovascular complications of diabetes. Clin Diabetes. 2008;26(2):77-82. https://doi.org/10.2337/diaclin.26.2.77

8. Brownlee M. The pathobiology of diabetic complications: A unifying mechanism Diabetes. 2005;54(6):1615-1625. https://doi.org/10.2337/diabetes.54.6.1615

9. Jamaludin $\mathrm{M}$, Nazratun NAH, Zanyantey AH, et al. Mechanism of diabetes-induced liver damage. The role of oxidative stress and inflammation. Sultan Qaboos University Med J. 2016;16(2):132-141. https://doi.org/10.18295/squmj.2016. 16.02.002

10. Hillenbrand A, Kiebler B, Schwab C, et al. Prevalence of non-alcoholic fatty liver disease in four different weight related patient groups: Association with smal bowel length and risk factors. BMC Res Notes. 2015;8:290. https://doi. org/10.1186/s13104-015-1224-7

11. Targher G, Bertolini L, Stefano R, et al. Nonalcoholic fatty liver disease is independently associated with an increased incidence of cardiovascular events in type 2 diabetic patients. Diabetes Care. 2007;30(8):2119-2121. https://doi. org/10.2337/dc07-0349

12. Targher G, Lonardo A, Byrne CD. Nonalcoholic fatty liver disease and chronic vascular complications of diabetes mellitus. Nat Rev Endocrinol. 2018;14(2): 99-114. https://doi.org/10.1038/nrendo.2017.173

13. Blendea MC, Thompson MJ, Malkani S. Diabetes and chronic liver disease: Etiology and pitfalls in monitoring. Clin Diabetes. 2010;28(4):139-144. https:// doi.org/10.2337/diaclin.28.4.139

14. Beena R, Thiruvenyada SG, Raja R. Incidence of glaucoma and diabetic retinopathy in patients with diabetes mellitus in a teaching hospital. J Med Dent Sci. 2017;4(5):31-35.

15. World Health Organisation. Prevention of blindness and deafness: Consultation on development of standards for characterization of vision loss and visual functioning. Geneva: WHO; 2003.

16. Resnikoff S, Pascolini D, Mariotti SP, et al. Global magnitude of visual impairment caused by uncorrected refractive errors in [homepage on the Internet]. 2004 [cited 2016 April 22]. Available from https://www.who.int/bulletin/volumes/86/ 1/07-041210/en/

17. Sparrow JM, Bron AJ, Brown NA, et al. Biometry of the crystalline lens in earlyonset diabetes. Br J Ophthalmol. 1990;74(11):654-660. https://doi.org/10.1136/ bjo.74.11.654

18. Gwinup G, Villarreal A. Relationship of serum glucose concentration to changes in refraction. Diabetes. 1976;25(1):29-31. https://doi.org/10.2337/diabetes. 25.1.29

19. Zaczek A, Olivestedt G, Zetterstrom C. Visual outcomes after phacoemulsification and IOL implantation in diabetic patients. $\mathrm{Br} J$ Ophthalmol. 1999;83(9): 1036-1041. https://doi.org/10.1136/bjo.83.9.1036

20. Denniston AK, Chakravarthy U, Zhu H, et al. The UK Diabetic Retinopathy Electronic Medical Record (UK DR EMR) Users Group, Report 2: Real world data for the impact of cataract surgery on diabetic macular edema. $\mathrm{Br} J$ Ophthalmol. 2017;101(12):1673-1678. https://doi.org/10.1136/bjophthalmol-2016-309838

21. Peto T, Sandi F, Kumar V. Making the most of cataract surgery in patients with diabetes. CEHJ. 2019;31(104):80-81.

22. Song BJ, Aiello LP, Pasquale LR. Presence and risk factors for glaucoma in patients with diabetes. Curr Diab Rep. 2016;16(12):124. https://doi.org/10.1007/s11892 016-0815-6

23. American Academy of Ophthalmology. The Eye M.D Association. Primary openangle glaucoma suspect: Preferred practice pattern. New York: Elsevier Inc; 2016.

24. Hodapp E, Parrish RK, Anderson DR. Clinical decisions in glaucoma. 1st ed. London: Mosby; 1993.

25. Ahmad SS. Glaucoma suspects: A practical approach. Taiwan J Ophthalmol 2018;8(2):74-81. https://doi.org/10.4103/tjo.tjo_106_17

26. Leydhecker W, Akiyama K, Neumann HG. Der intraokulare druk gesunder menschlicher augen. Klin Monatsbl Augenheilkd. 1958;133:662-670. 
27. Bhaisakhiya S, Garg P, Singh S. Association between glycemic control and intraocular pressure in patients with type 2 diabetes mellitus. Natl J Physiol Pharm Pharmacol. 2016;7(1):43-46. https://doi.org/10.5455/njppp.2016.6.0718813072016

28. Hymowitz MB, Chang D, Feinberg EB, et al. Increased intraocular pressure and hyperglycaemic level in diabetic patients. PLoS One. 2016;11(3):e0151833. https://doi.org/10.1371/journal.pone.0151833

29. Shrivastava SR, Shrivastava PS, Ramasamy J. Role of self-care in management of diabetes mellitus. J Diabetes Metab Disord. 2013;12(1):14. https://doi. org/10.1186/2251-6581-12-14

30. Sithole HL. Oduntan OA. Eye health promotion in South Africa primary health care system. S Afr Optom. 2010;69(4):200-206. https://doi.org/10.4102/aveh.v69i4.144

31. Davis MD, Fisher MR, Gangnon RE. Risk factors for high risk proliferative diabetic retinopathy and severe visual loss: Early Treatment Diabetic Retinopathy Study Report No.18. Invest Ophthalmol Vis Sci. 1998;39(2):233-252.

32. Harizman N, Oliveria C, Chiang A, et al. The ISNT rule and differentiation of norma from glaucomatous eyes. Arch Ophthalmol. 2006;124(11):1579-1583. https:// doi.org/10.1001/archopht.124.11.1579

33. Baba D, Krishnan M, Bhaskaran S, et al. Prevalence of diabetic retinopathy and correlation with systemic risk factors in type 2 diabetes mellitus in a tertiary care hospital. SJAMS. 2015;3(7C):2659-2664.
34. Kiziltoprak $\mathrm{H}$, Tekin $\mathrm{K}$, Inanc $\mathrm{M}$, et al. Cataract in diabetes mellitus. World Diabetes. 2019;10(3):140-153. https://doi.org/10.4239/wjd.v10.i3.140

35. Saxena S. Mitchell P, Rochtchina E. Five-year incidence of cataract in older persons with diabetes and pre-diabetes. Ophthalmic Epidemiol. 2004;11(4):271-277. https://doi.org/10.1080/09286580490510733

36. Pollreisz A, Schmidt-Erfurth U. Diabetic cataract - Pathogenesis, epidemiology and treatment. J Ophthalmol. 2010;2010:a608751. https://doi.org/10.1155/2010/ 608751

37. Cairncross JP, Steinberg WJ, Labuschagne MJ. Prevalence of eye pathology in a group of diabetic patients at National District Hospital Outpatient Department in Bloemfontein, South Africa. Afr J Health Care Fam Med. 2017;9(1):e1-e7. https:// doi.org/10.4102/phcfm.v9i1.1440

38. Khan T, Bertram MY, Jina R, et al. Preventing diabetes blindness: Cost effectiveness of screening a programme using a digital non-mydriatric fundus photography for di photography for diabetic retinopathy in a primary health care setting in South diabres.2013.05.006

39. Rajalakshmi R, Subashini R, Anjana RM, et al. Automated diabetic retinopathy detection in smartphone-based fundus photography using artificial intelligence. Eye. 2018;32(6):1138-1144. https://doi.org/10.1038/s41433-018-0064-9 


\section{Appendix 1}

\section{Context-input-process-output approach model}

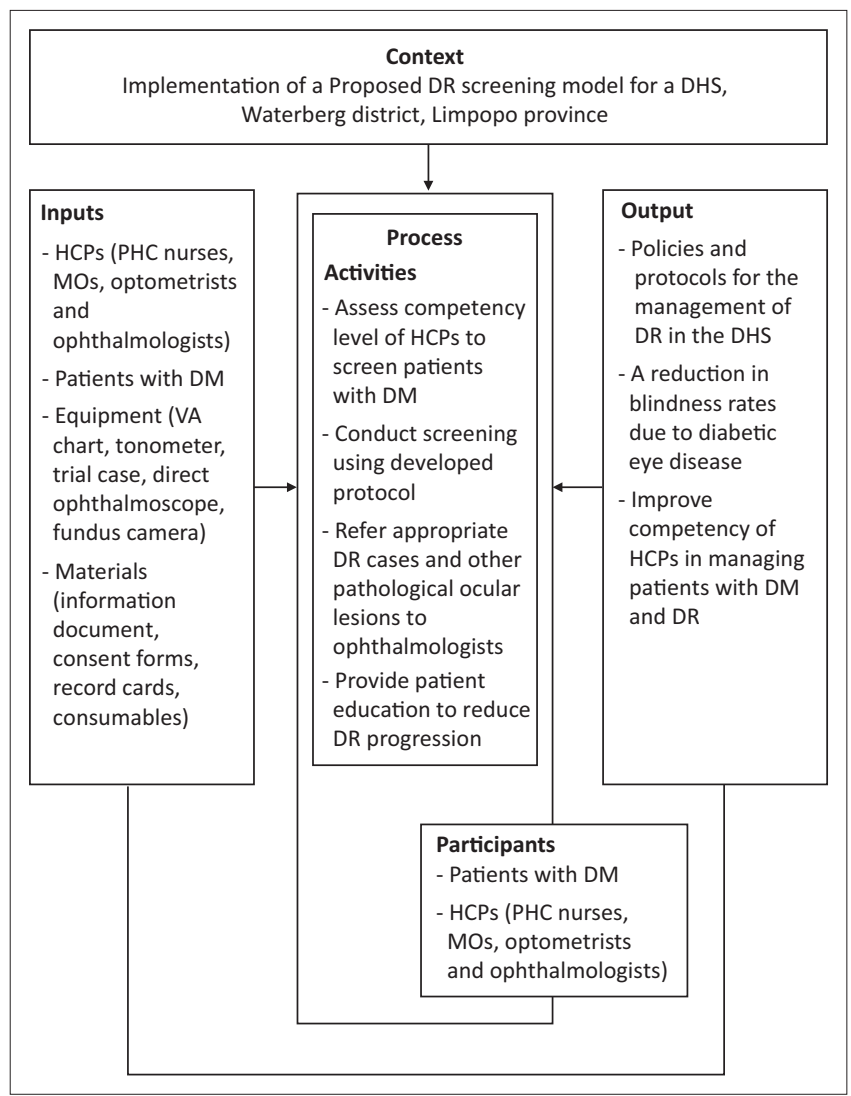

HCPs, healthcare practitioners; PHC, primary healthcare; MOs, medical officers; DM, diabetes mellitus; VA, visual acuity; DR, diabetic retinopathy; DHS, district health systems. 